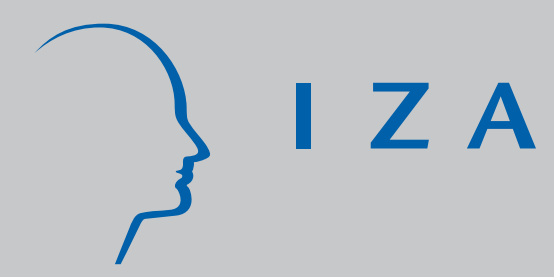

IZA DP No. 529

Incapacity Benefits and Employment Policy

J. Michael Orszag

Dennis Snower

J uly 2002 


\title{
Incapacity Benefits and Employment Policy
}

\author{
J. Michael Orszag \\ Watson Wyatt and IZA Bonn \\ Dennis Snower \\ Birkbeck College, University of London, \\ CEPR and IZA Bonn
}

\author{
Discussion Paper No. 529 \\ July 2002
}

\author{
IZA \\ P.O. Box 7240 \\ D-53072 Bonn \\ Germany \\ Tel.: +49-228-3894-0 \\ Fax: +49-228-3894-210 \\ Email: iza@iza.org
}

This Discussion Paper is issued within the framework of IZA's research area The Welfare State and Labor Markets. Any opinions expressed here are those of the author(s) and not those of the institute. Research disseminated by IZA may include views on policy, but the institute itself takes no institutional policy positions.

The Institute for the Study of Labor (IZA) in Bonn is a local and virtual international research center and a place of communication between science, politics and business. IZA is an independent, nonprofit limited liability company (Gesellschaft mit beschränkter Haftung) supported by the Deutsche Post AG. The center is associated with the University of Bonn and offers a stimulating research environment through its research networks, research support, and visitors and doctoral programs. IZA engages in (i) original and internationally competitive research in all fields of labor economics, (ii) development of policy concepts, and (iii) dissemination of research results and concepts to the interested public. The current research program deals with (1) mobility and flexibility of labor, (2) internationalization of labor markets, (3) the welfare state and labor markets, (4) labor markets in transition countries, (5) the future of labor, (6) evaluation of labor market policies and projects and (7) general labor economics.

IZA Discussion Papers often represent preliminary work and are circulated to encourage discussion. Citation of such a paper should account for its provisional character. A revised version may be available on the IZA website ( $\underline{w w w . i z a . o r g}$ ) or directly from the author. 
IZA Discussion Paper No. 529

July 2002

\section{ABSTRACT}

\section{Incapacity Benefits and Employment Policy*}

The paper explores the employment implications of allowing people the opportunity of using a portion of their incapacity benefits to provide employment vouchers for employers that hire them. The analysis indicates that introducing this policy could increase employment, raise the incomes of incapacity benefit recipients, and reduce employers' labor costs. The analysis explicitly derives the optimal voucher, i.e. the voucher that maximizes employment at no extra budgetary cost. This voucher is shown to depend on the size of incapacity benefits, the separation rate in the absence of the voucher, and the degree of displacement; but it does not depend on the hiring rate. Numerical calculations show the optimal voucher to be large by the standards of many existing employment subsidies.

JEL Classification: J23, J24, J31, J32, J64

Keywords: incapacity benefits, employment policy, labor force participation

Dennis Snower

Department of Economics

Birkbeck College

University of London

7 Gresse Street

London W1P 1PA

Tel.: +44 (207) 6316408

Email: dsnower@economics.bbk.ac.uk

\footnotetext{
* The authors wish to thank Jean-Marc Salou of the OECD for his help on data issues.
} 


\section{Introduction}

In some OECD countries, such as the Netherlands and the United Kingdom, incapacity (or disability) benefits play a significant role in depressing labor force participation. This is recognized to be a serious problem since low participation rates mean that the number of people producing goods and services is low, and that the people employed need to support a large number of unproductive ones. Thus tax rates on productive individuals need to be high; these tax rates, in turn, discourage the productive individuals from working as hard as they otherwise would and also induce some to leave the labor force. Consequently, labor force participation rates fall even further, and so on. Countries supporting large numbers of people on incapacity benefits are particularly likely to fall into this high-tax/low-participation trap, other things being equal.

This paper explores a new policy approach to this problem, namely, giving the recipients of incapacity benefits the option to use a portion of these benefits to provide employment vouchers for employers that hire them. ${ }^{2}$ This policy may be called the "incapacity benefit transfer program" (IBTP), since it involves transferring some of the money that pays for incapacity benefits to pay for employment vouchers instead.

The effectiveness of the policy naturally depends on the identity of the target group, the group defined as incapacitated. For simplicity, we will restrict our analysis to the "elderly incapacitated," e.g. recipients of incapacity benefits who are over 45 years of age. In the UK and the Netherlands, as in other OECD countries, most of these people enter their incapacitated status after going though a period of unemployment. According to widespread anecdotal evidence, their stress of being unemployed together with their perceived low chances of re-employment are significant factors leading them to claim incapacity. The distinguishing feature of the elderly incapacitated, as compared with other incapacitated people, is that only a very small proportion of them exit from incapacity status prior to retirement. This means that the problem of "deadweight" - giving employment vouchers to

\footnotetext{
${ }^{2}$ This policy is an extension of the Benefit Transfer Program (BTP) to incapacity recipients. The employment effects of the BTP have been analyzed in Snower $(1994,1996)$ and Orszag and Snower (2000).
} 
people who would have found employment anyway - is particularly small for this target group.

This target group my be divided into three categories: ${ }^{3}$

1) those who are so incapacitated that they are unable to do any productive work,

2) those who are able to do some productive work but whose incapacity prevents them from finding employment at the prevailing wages, and

3) those who are able to find employment at the prevailing wages but who choose to be classified as incapacitated since they prefer receiving incapacity benefits to accepting the available jobs.

The IBTP is aimed at the second and third groups.

The IBTP has the following salient features: ${ }^{4}$

- The size of a person's employment voucher is positively related to the size of that person's incapacity benefit. In other words, the more money the government is spending to support a currently incapacitated person, the greater the incentive it offers that person to become employed.

- The IBTP is voluntary: Only those potential employers and incapacity benefit recipients who wish to take advantage of the employment vouchers option need do so.

- Once a person has found a job through this program, the employment vouchers to a particular employer remain in place for a number of years. Thereafter, the incapacitated person continues to qualify for such vouchers, but not with his/her original employer. ${ }^{5}$

\footnotetext{
${ }^{3}$ We clearly do not imply that people's membership of these categories remains unchanged through time. Rather, people can and do move from one category to another, and from any of these categories into other labor market states (such as employment, unemployment, or inactivity).

${ }^{4}$ In 1992 the UK introduced the "Disability Working Allowance" (DWA) that is superficially similar to the proposed policy. The DWAs are awarded for a period of only six months. They have strict upper limits unrelated to the size of incapacity benefits. Recipients of DWAs must have low incomes. These various provisions all reduce the effectiveness of the allowance and limit the number of eligible recipients. By contrast, the policy proposed here makes the employment vouchers depend solely on the size of the incapacity benefits.

${ }^{5}$ The reason for this provision is that some employers may have an incentive to retain their incapacitated employees after their employment vouchers have run out. The resulting saving to the government, which pays neither incapacity benefits nor employment vouchers to these people, enables the government to provide more generous vouchers to those people remaining on the employment voucher scheme.
} 
- Incumbent employees who believe that they have been displaced by previously incapacitated recruits have a right of complaint. Such complaints are to be investigated by an independent body. If the complaints are considered justified, the firm responsible is fined.

- The recipients of the employment vouchers have the option of using a fraction of these vouchers to induce employers to continue making incapacity benefit payments out of any existing private insurance funds. ${ }^{6}$

- In order to avoid encouraging currently employed, unemployed or inactive people to classify themselves as incapacitated in order to take advantage of the employment vouchers, the IBTP restricts these vouchers to those who have been incapacitated and jobless for at least a specified period of time, say, 2 years. The aim of this restriction is to make it very costly to achieve incapacity status.

The IBTP is meant to raise the take-home pay of the newly recruited (previously incapacitated) workers, while at the same time reducing their cost to the employers. The difference between what the employees receive and what the employers pay is the fraction of the incapacity benefit that has been transferred to employment vouchers.

When people draw incapacity benefits, the government bears the cost of supporting them single-handedly. But when they transfer their incapacity benefits to employment vouchers, the government shares this cost with the firms that hire them. Since the amount that the government spends on the employment vouchers is set so as not to exceed what would have spent anyway on incapacity benefits, the reduction in incapacity and consequent increase in employment can be achieved at no extra budgetary cost.

The IBTP has an obvious strength vis-à- vis other employment subsidies to nonemployed people: The absence of significant deadweight for incapacity benefit recipients means that self-financing employment vouchers to these people can be more generous than

${ }^{6}$ In countries where private incapacity insurance is significant (as through occupational pension systems), the recipients of private-sector incapacity benefits tend to be skilled and comparatively well-paid. This provision is an attempt to counteract the danger that these people may have no incentive to convert their government-provided incapacity benefits into employment vouchers since they would thereby lose their entitlements to their privateinsurance incapacity benefits. 
the corresponding vouchers to non-employed people with otherwise identical characteristics.

The aim of this paper is to present some simple arithmetic on the optimal size of employment vouchers to incapacity benefit recipients. The emphasis is on empirical tractability. Thus, rather assessing the effectiveness of the IBTP in a sophisticated general equilibrium model, derived from choice theoretic foundations, we evaluate the policy in the context of a simple macro model of the labor market with a small number of empirically identifiable parameters. This model is meant to provide a straightforward computational framework for practical implementation of the IBTP. (However we provide illustrative microfoundations for our behavioral relations in the appendix.)

The results of our analysis are striking. We show that, when there is no deadweight and the elasticity labor demand for these recipients is greater than zero, it is always possible to stimulate employment through self-financing employment vouchers. Moreover, we indicate that not only are the optimal self-financing employment vouchers always positive, but - for plausible values of the autonomous separation rate and the rate of displacement they constitute a large fraction of the existing incapacity benefits.

The paper is organized as follows. Section 2 surveys some evidence on labor force participation rates and incapacity benefits and discusses how the latter contribute to the former. Section 3 summarizes how the IBTP may work in the absence of displacement (i.e. when the implementation of the policy does not increase the rate at which incumbent employees are fired). Section 4 investigates the implications of displacement for the effectiveness of the policy. Section 5 concludes.

\section{Incapacity Benefits and Labor Force Participation}

Low labor force participation rates appear to be endemic to the institutional structures of various European countries. For example, as shown in Table 1, Belgium, France, Germany, Italy, Ireland, the Netherlands and Spain all have labour force participation rates below $70 \%$. 


\begin{tabular}{ll} 
Country & Participation Rate \\
Belgium & $65.2 \%$ \\
Denmark & $80 \%$ \\
Finland & $74.2 \%$ \\
France & $68 \%$ \\
Germany & $72.2 \%$ \\
Ireland & $67.4 \%$ \\
Italy & $60.3 \%$ \\
Japan & $72.5 \%$ \\
Netherlands & $74.6 \%$ \\
Norway & $80.7 \%$ \\
Portugal & $71.1 \%$ \\
Spain & $65.3 \%$ \\
Sweden & $78.9 \%$ \\
Switzerland & $81.8 \%$ \\
United Kingdom & $76.6 \%$ \\
United States & $77.2 \%$ \\
\hline
\end{tabular}

Table 1: Participation Rates of Individuals Aged 15-64. Source: OECD Labour Market Statistics ${ }^{7}$

One practical implication of a low labor force participation rate is a high "inactivity ratio," i.e. the ratio of the number of people receiving benefits to the number of active workers. It is often suggested that one reason for the high inactivity ratios in some EC countries is that these countries spend significant percentages of their GDP on incapacity benefits. In most EC countries expenditures on sickness benefits are more than twice as high as expenditures on unemployment benefits, and disability benefit expenditures are of the same order of magnitude as unemployment benefit expenditures. ${ }^{8}$ In the UK, government

${ }^{7}$ Data is available online at:

http://www.oecd.org/scripts/cde/members/LFSINDICATORSAuthenticate.asp ${ }^{8}$ For example, sickness, disability, and unemployment benefit expenditures as percentage of total social protection expenditures in 1993 were: $23 \%, 9 \%$, and 10\% in Belgium; 19\%, 8\% and $13 \%$ in Denmark; 26\%, 6\%, and 9\% in France; 28\%, 9\%, and 6\% in Germany; 30\%, $7 \%$, and $15 \%$ in Ireland; $22 \%, 7 \%$, and $2 \%$ in Italy; $22 \%, 22 \%$, and $9 \%$ in the 
spending for sickness and disability has quadrupled over the past two decades, and $40 \%$ of working-age recipients of government benefits are people claiming sickness and disability benefits.

The steep increases in expenditures on incapacity benefits in some EC countries, without any corresponding evidence of a marked deterioration in national health, suggests that financial incentives may have a significant role to play in determining the number of incapacity benefit recipients. ${ }^{9}$ Viewed in this light, the effects of incapacity benefits on the labor market may to some extent be understood as analogous to the effects of unemployment benefits. Just as unemployment benefits augment the problem whose effects they are meant to mitigate, so incapacity benefits do so as well. ${ }^{10}$

The analogy is worth taking seriously. Unemployment benefits discourage job search; they also lengthen the duration of job search for those who have not been entirely discouraged, since they raise the returns from not finding a job. Beyond that, they put upward pressure on wages, induce incumbent workers to take greater risks of dismissal, and induce firms to increase their rate of labor turnover. Insofar as financial considerations are relevant in determining the number of incapacity recipients, these problems are present for incapacity benefits as well.

In the next section we examine how incapacity benefit transfers may alleviate this problem.

\section{A Simple Model of Incapacity Benefit Transfers}

We consider the effects of the IBTP in the context of a transparently simple model. To begin with, we make the simplifying assumption that people in our target group - the elderly incapacitated - can be in one of two states, employment or inactivity. It is not necessary to consider the state of unemployment in this context, since people in the target

Netherlands; and 19\%, 12\%, and 6\% in the UK. Observe that the UK and particularly the Netherlands are extreme outliers in this respect.

${ }^{9}$ The ageing of the population has doubtlessly played a role as well.

${ }^{10}$ This is not to deny, however, that incapacity benefits may at the same time be playing a positive role, such as prolonging the lives of the incapacitated. 
group have no incentive to claim unemployment status: incapacity benefits tend to be more generous than unemployment benefits.

Let $h$ be the probability that a worker is hired, and $f$ be the probability of a separation (where $f$ stands for "firing," one possible source of separation). The target population $P$ is assumed constant through time. Let $N_{t}$ and $I_{t}$ be the numbers of employed and incapacitated people (respectively) out of the target group in period $t$. Then $N_{t}+I_{t}=P$. The change in employment is the difference between the number of people hired and the number separated:

$$
\Delta N_{t}=N_{t}-N_{t-1}=h I_{t-1}-f N_{t-1}
$$

As noted in Section 1, the target group has small chance of receiving job offers in the absence of incapacity benefits. Thus, for simplicity, we assume that there is no "deadweight". Our specification of the hiring rate is very general: we merely assume that it is some positive function of the employment voucher ratio $v$, i.e. the ratio of the voucher to the wage:

$$
h=h(v), \quad h^{\prime}>0
$$

To keep our computations simple, we assume that all incapacity benefit recipients receive vouchers of the same magnitude, and that the voucher is paid in each period of analysis. For the moment we also make the simplifying assumption that the anti-displacement provision of Section 1 effectively prevents displacement, and thus the separation rate is a constant (unaffected by the employment voucher):

$$
f=b
$$

where $b$ is a positive constant. (The effectiveness of the IBTP on the presence of displacement is examined in the next section. Illustrative microfoundations for the hiring and separation functions are given in the appendix.)

In the long run, where $N_{t}$ and $I_{t}$ are constant, the level of employment is

$$
N(v)=\frac{h(v)}{h(v)+b} P
$$

and the corresponding long-run level of incapacity is

$$
I(v)=\frac{b}{b+h(v)} P
$$

by the hiring function (2) and the separation function (3). 
For simplicity, suppose that the government's policy problem is to find the magnitude of the employment voucher that maximizes the level of employment, subject to a government budget constraint, which may be specified as follows.

Since the number of incapacitated people hired in each period is $h(v) I(v)$, the total cost of the employment vouchers (per period of time) to the government is $v h(v) I(v)$. This cost must be set against the "voucher revenue", which the total amount that the government saves on incapacity benefits (per period of time) due to the voucher-induced rise in the employment level.

In particular, let $I(v)$ and $I(0)$ be the long-run incapacity levels in the presence and absence of the voucher $v(v>0)$, respectively. Let the incapacity benefit $\beta$ be a positive constant, measured in units of national income. Then the amount the government is able to save on incapacity benefits due to the employment vouchers is $\beta(I(0)-I(v))$.

If the IBTP is to be costless to the government, then the government budget constraint is

$$
v h(v) I(v) \leq \beta(I(0)-I(v))
$$

In other words, the cost of the employment vouchers (the left-hand expression) must not exceed the voucher revenue from reduced incapacity (the right-hand expression).

To find the employment voucher that maximizes long-term employment (4) subject to the government budget constraint, it is convenient to express the voucher cost as

$$
v h(v) I(v)=v h(v) \frac{b}{b+h(v)} P
$$

and the voucher revenue as

$$
\beta(I(0)-I(v))=\beta \frac{h(v)}{b+h(v)} P
$$

This restatement can provide an intuitive understanding of the optimal employment voucher policy. For this purpose, the government budget constraint may be written as

$$
v h(v) \frac{b}{b+h(v)} P \leq \beta \frac{h(v)}{b+h(v)} P .
$$

by equations (7) and (8). Expressing these terms as magnitudes per hired incapacitated person (i.e. dividing both sides of equation (9) by $(b h(v) /(b+h(v))) P$, the government budget constraint becomes 


$$
v \leq \frac{\beta}{b}
$$

There are two further constraints on the size of the voucher, namely, a non-negativity constraint:

$$
v \geq 0
$$

and a constraint that specifies that the hiring rate cannot exceed unity, so that

$$
h(v) \leq 1 .
$$

Differentiating equation (4), we find that the voucher stimulates employment in the long run:

$$
\frac{\partial N}{\partial v}=\frac{h^{\prime}(v) b}{(b+h(v))^{2}} P>0 .
$$

Consequently the government's problem of maximizing employment through a balanced budget voucher policy reduces to the problem of finding the highest voucher that satisfies the constraints (10)-(12). Thus the optimal voucher is

$$
v^{*}=\min \left[\max \left(\frac{\beta}{b}, 0\right), h^{-1}(1)\right]
$$

and since $\beta / b>0$, this solution reduces to

$$
v^{*}=\min \left[\frac{\beta}{b}, h^{-1}(1)\right] .
$$

Note furthermore that the corner-point solution can be ignored, since it would imply that all the incapacitated people are hired in any given period. Thus we are left with the interior solution for the optimal voucher:

$$
v^{*}=\frac{\beta}{b}
$$

i.e. the value of the optimal employment voucher must be equal to the ratio of the incapacity benefit to the separation rate. Since estimates of the relevant incapacity benefits and separation rates are straightforward to obtain, this policy is easy to implement in practice.

Equation (15) is a striking result. Note that when the separation rate is unity, the optimal voucher is exactly equal to the incapacity benefit. In practice, however, we may expect that some of the incapacitated people who are employed on account of the voucher do not separate when the voucher payments to a particular employer run out, on account of the human capital that these incapacitated people acquire during their subsidized job tenure. 
Then, with a separation rate less than unity, equation (15) then implies that the optimal voucher payment, per period of time, must exceed the existing incapacity payment. For example, if the separation rate is $90 \%$, then the optimal voucher must exceed the incapacity benefit by about $11 \%$; and if the separation rate is $80 \%$, then the optimal voucher is $25 \%$ higher than the incapacity benefit. The reason of course is that when the separation rate is less than unity, private-sector employment of the incapacitated people not only enables the government not to saves the current incapacity benefit, but also so save the future incapacity benefits for those employers who do not dismiss their incapacitated employees once the subsidy runs out. This result holds regardless of the way in which hiring depends on the voucher. In the absence of displacement, as the analysis shows, the vouchers does not depend on the hiring rate at all.

\section{Incapacity Benefit Transfers in the Presence of Displacement}

Anti-displacement provisions (such as the one specified in Section 1) are never insurmountable in practice. The reason of course is that (i) such provisions are unlikely be a complete deterrent to displacement and (ii) they cannot prevent cannot firms that hire subsidized new recruits from competing with firms that don't and thereby leading to layoffs at the latter firms.

This section outlines how the optimal employment voucher policy is to be formulated our model is extended to take account of the possibility of displacement. So, instead of taking the separation rate to be a constant, let us assume that there is a positive linear relation between the separation rate and the size of the voucher:

$$
f=b+c v
$$

where $c$ is a positive constant. Thus an increase in the voucher not only induces employers to hire more incapacitated people, but it also induces more separation through displacement of other employees.

Substituting equations (2) and (3') into (4), we can obtain the long-run level of employment: 


$$
N(v)=\frac{h(v)}{b+c v+h(v)} P
$$

and the long-run level of incapacity:

$$
I(v)=\frac{b+c v}{b+c v+h(v)} P .
$$

Thus the cost of the voucher policy is

$$
v h(v) I(v)=v h(v) \frac{b+c v}{b+c v+h(v)} P
$$

and the voucher revenue is

$$
\beta(I(0)-I(v))=\beta\left[1-\frac{b+c v}{b+c v+h(v)}\right] P=\beta\left[\frac{h(v)}{b+c v+h(v)}\right] P .
$$

Expressing the voucher cost and voucher revenue as magnitudes per incapacitated person, the government budget constraint becomes

$$
v h(v) \leq \beta \frac{h(v)}{b+c v}
$$

(Observe that voucher cost and voucher revenue both rise proportionally with the hiring rate and thus the maximal voucher consistent with the constraint (18) does not depend on the hiring rate.) The constraint (18), together with the boundary conditions (11) and (12), implies that the optimal voucher is

$$
v^{*}=\min \left[\max \left(\frac{-b+\sqrt{b^{2}+4 c \beta}}{2 c}, 0\right), h^{-1}(1)\right]
$$

Ignoring the corner-point solution (for the reasons given above) and noting that

$$
\frac{-b+\sqrt{b^{2}+4 c \beta}}{2 c}>0
$$

solution (19) reduces to

$$
v^{*}=\frac{-b+\sqrt{b^{2}+4 c \beta}}{2 c}
$$

This, too, is a striking result. First, observe that the optimal voucher is always positive, which means that it is always feasible to increase employment and reduce incapacity payments through the voucher policy. Second, the optimal voucher rises with the square root of the incapacity benefit (rather than in proportion to the incapacity benefit, as in the 
absence of displacement). Third, the optimal voucher falls as the displacement coefficient $c$ rises. ${ }^{11}$

The following table describes the optimal voucher $v^{*}$ (as a fraction of the average wage) for various values of the autonomous separation rate $b$, the displacement coefficient $c$, and the incapacity benefit $\beta$ (as a fraction of the average wage):

$\begin{array}{llll}\boldsymbol{b} & \boldsymbol{c} & & \boldsymbol{v}^{*} \\ & & & \\ 0.8 & 0.1 & 0.3 & 0.359 \\ & & 0.4 & 0.472 \\ & & 0.5 & 0.583 \\ & & & \\ 0.95 & 0.5 & 0.3 & 0.276 \\ & & 0.4 & 0.355 \\ & & 0.5 & 0.429 \\ & & & \\ 1 & & & \\ & & & \\ & & 0.3 & 0.26 \\ & & 0.4 & 0.333 \\ & & 0.5 & 0.403\end{array}$

It goes without saying, that in all of these cases, the optimal self-financing employment vouchers are large by the standards of many existing employment subsidies. On account of their size, they may well have a significant impact on the employment prospects of the target group.

\footnotetext{
${ }^{11}$ In other words, the derivative of the first right-hand term of equation (19') with respect to $c$ is negative.
} 


\section{Concluding Remarks}

There is a straightforward case for allowing people to use a fraction of their incapacity benefits to provide employment vouchers for employers that hire them. It is, quite simply, that it expands the choices available to the incapacity benefit recipients and their potential employers. The current incapacity benefit systems leave large number of recipients jobless since they are unwilling to work at the wages that firms would be willing to offer them. What the IBTP does is to reduce the labor costs of these workers (through the vouchers to the firms) and to raise their take-home pay (since the vouchers induce the firms to raise their wage offers). If the magnitude of the vouchers is set appropriately, an increase in employment can be achieved without extra budgetary cost to the government.

In order for these new opportunities to be maximally available, it is clearly undesirable to impose wage restrictions on the incapacitated recruits and their employers, such as setting the minimum wage as an upper bound. Nor is it desirable to cap the size of the employment vouchers on the basis of factors unrelated to the size of the incapacity benefits. Nor is it wise to limit the duration of the incapacity benefits. Such restrictions would severely limit the gains the incapacitated people could achieve from the policy and thus seriously impede its takeup.

Finally, the rationale for the IBTP suggests that it is needless for the government to bear the cost of incapacity benefits all on its own if it is possible to share this some of cost voluntarily with the private sector and thereby raise aggregate employment and production.

\section{Appendix}

This appendix provides extremely simple, illustrative microfoundations for the hiring and separation functions in Section 3. The aim is clearly not to provide a full-blown general equilibrium model within which the IBTP can be assessed, but rather to provide a transparent theoretical example of how the hiring and separation decisions, which drive our results, can given a choice theoretic rationale. 
Suppose that each worker in the target group has a productivity $\alpha$, a random variable that is distributed uniformly and iid across workers over the range [0,1]. Workers are infinitely lived. Let the reservation wage of workers in the target group be $r(0<r<1)$, a constant, and let this be the wage employers offer the workers in the target group. The profit generated by a worker is $\alpha-r$. An employee separates when $\alpha-r<0$. Given the distribution of $\alpha$, the separation rate is $f=r$.

A worker is hired when $\alpha-r+v r+\sum_{t=1}^{\infty}(1-f)(1 / 2-r)>0$, where $1 / 2$ is the mean value of $\alpha$. Rewriting this condition and substituting that $f=r$, we obtain that a worker is hired when $\alpha>\beta-v r$, where $\beta=r-(1-r)(1 / 2-r) / r$, a constant. Given the distribution of $\alpha$, the hiring rate is $h=1-\beta+v r$.

\section{References}

Orszag, Michael and Dennis J. Snower (2000), “The Effectiveness of Employment Vouchers: A Simple Approach," German Economic Review, Vol. 1, Issue 4, 385-419.

Snower, Dennis J. (1994), “Converting Unemployment Benefits into Employment Subsidies," American Economic Review, Papers and Proceedings, 84(2), 65-70. Snower, Dennis J. (1996), “The Simple Economics of Benefit Transfers,” in Dehesa and Snower (eds), Unemployment Policy, Cambridge: Cambridge University Press, 163198. 


\section{IZA Discussion Papers}

\begin{tabular}{|c|c|c|c|c|}
\hline No. & Author(s) & Title & Area & Date \\
\hline 512 & $\begin{array}{l}\text { C. Belzil } \\
\text { J. Hansen }\end{array}$ & $\begin{array}{l}\text { A Structural Analysis of the Correlated Random } \\
\text { Coefficient Wage Regression Model }\end{array}$ & 6 & $06 / 02$ \\
\hline 513 & $\begin{array}{l}\text { C. Belzil } \\
\text { J. Hansen }\end{array}$ & $\begin{array}{l}\text { Earnings Dispersion, Risk Aversion and } \\
\text { Education }\end{array}$ & 6 & $06 / 02$ \\
\hline 514 & F. Schneider & $\begin{array}{l}\text { The Size and Development of the Shadow } \\
\text { Economies of } 22 \text { Transition and } 21 \text { OECD } \\
\text { Countries }\end{array}$ & 4 & $06 / 02$ \\
\hline 515 & $\begin{array}{l}\text { J. Hurley } \\
\text { R. Vaithianathan } \\
\text { T. F. Crossley } \\
\text { D. Cobb-Clark }\end{array}$ & $\begin{array}{l}\text { Parallel Private Health Insurance in Australia: } \\
\text { A Cautionary Tale and Lessons for Canada }\end{array}$ & 3 & $06 / 02$ \\
\hline 516 & H. Bonin & $\begin{array}{l}\text { Eine fiskalische Gesamtbilanz der Zuwanderung } \\
\text { nach Deutschland }\end{array}$ & 7 & $06 / 02$ \\
\hline 517 & E. Tekin & $\begin{array}{l}\text { Child Care Subsidies, Wages, and Employment } \\
\text { of Single Mothers }\end{array}$ & 3 & $06 / 02$ \\
\hline 518 & $\begin{array}{l}\text { P. Carneiro } \\
\text { J. J. Heckman }\end{array}$ & $\begin{array}{l}\text { The Evidence on Credit Constraints in } \\
\text { Post-Secondary Schooling }\end{array}$ & 5 & $06 / 02$ \\
\hline 519 & $\begin{array}{l}\text { S. Cohen } \\
\text { Z. Eckstein }\end{array}$ & $\begin{array}{l}\text { Labor Mobility of Immigrants: Training, } \\
\text { Experience, Language and Opportunities }\end{array}$ & 1 & $06 / 02$ \\
\hline 520 & U. Sunde & $\begin{array}{l}\text { Unobserved Bilateral Search on the Labor } \\
\text { Market: A Theory-Based Correction for a } \\
\text { Common Flaw in Empirical Matching Studies }\end{array}$ & 1 & $06 / 02$ \\
\hline 521 & $\begin{array}{l}\text { U. Sunde } \\
\text { R. Fahr }\end{array}$ & $\begin{array}{l}\text { Employment Status, Endogenous Regional } \\
\text { Mobility, and Spatial Dependencies in Labor } \\
\text { Markets }\end{array}$ & 1 & $06 / 02$ \\
\hline 522 & $\begin{array}{l}\text { S.-Å. Dahl } \\
\varnothing . \text { A. Nilsen } \\
\text { K. Vaage }\end{array}$ & $\begin{array}{l}\text { Gender Differences in Early Retirement } \\
\text { Behaviour }\end{array}$ & 3 & $06 / 02$ \\
\hline 523 & $\begin{array}{l}\text { J. Falkinger } \\
\text { V. Grossmann }\end{array}$ & $\begin{array}{l}\text { Workplaces in the Primary Economy and Wage } \\
\text { Pressure in the Secondary Labor Market }\end{array}$ & 3 & $07 / 02$ \\
\hline 524 & $\begin{array}{l}\text { J. J. Dolado } \\
\text { F. Felgueroso } \\
\text { J. F. Jimeno }\end{array}$ & $\begin{array}{l}\text { Recent Trends in Occupational Segregation by } \\
\text { Gender: A Look Across the Atlantic }\end{array}$ & 2 & $07 / 02$ \\
\hline 525 & $\begin{array}{l}\text { J. J. Heckman } \\
\text { C. Heinrich } \\
\text { J. Smith }\end{array}$ & The Performance of Performance Standards & 6 & $07 / 02$ \\
\hline 526 & $\begin{array}{l}\text { E. Leuven } \\
\text { H. Oosterbeek }\end{array}$ & $\begin{array}{l}\text { A New Approach to Estimate the Wage Returns } \\
\text { to Work-Related Training }\end{array}$ & 6 & $07 / 02$ \\
\hline 527 & J. C. van Ours & The Locking-in Effect of Subsidized Jobs & 4 & $07 / 02$ \\
\hline 528 & $\begin{array}{l}\text { P. Manzini } \\
\text { M. Mariotti }\end{array}$ & $\begin{array}{l}\text { Arbitration and Mediation: An Economic } \\
\text { Perspective }\end{array}$ & 3 & $07 / 02$ \\
\hline 529 & $\begin{array}{l}\text { J. M. Orszag } \\
\text { D. Snower }\end{array}$ & Incapacity Benefits and Employment Policy & 3 & $07 / 02$ \\
\hline
\end{tabular}

